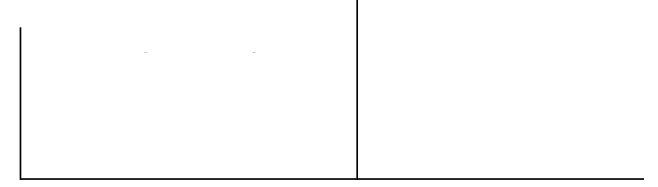

Rev. Latinoam. Psicop. Fund. VII, 4, 192-199

\title{
Todas as vias levam ao hábito? Introduzindo William James
}

G uilherme G utman

Embora a melhor imagem de William James (1842-1910) não seja a de um profeta pregando no deserto, envolto em pele de camelo, alimentando-se de mel silvestre e de gafanhotos, ela pode assaltar a mente do leitor em alguns pontos de sua obra. Em seus textos sobre hábito (1887, 1890, 1892, 1899a, 1899b) há a presença plúmbea de uma ética quase religiosa.

Também não é a imagem mais fidedigna de James a de um professor severo, de ar circunspecto e de dedo em riste, apontando aos seus pupilos o caminho seguro para a constituição de um caráter reto. Todavia, ela é sugerida pela profusão de recomendações morais encontradas em algumas de suas preleções de Talks to teachers (1899).

$\mathrm{O}$ fato é que as duas imagens evocadas não fazem justiça ao semblante de James. Em parte pelo modo terno com que ele se dirige a uma audiência composta de estudantes em "The gospel of relaxation” (1899b), mas sobretudo pela presença, nestes e noutros textos, de alguns elementos que autorizam a compreensão de suas posições morais em outros termos. James escapa da acusação de moralismo por fundar suas prescrições éticas em um conjunto teórico sólido e, o que parece mais interessante, por vincular interesse ético à ação. O rótulo de moralismo vazio parece mais adequado a agentes de 
prescrições normativas embaladas por conceitos imutáveis como raça, classe ou linhagem familiar, o que, indubitavelmente, não é o caso de James. Além de depoimentos que atestam o quanto ele era, no âmbito político, progressista para sua época (cf. Angier, 1943; Myers, 1986; ${ }^{1}$ Posnock, 1997), sua teoria da ação é naturalista, o que equivale a dizer, orientada pela idéia nuclear de contingência. ${ }^{2}$

Por alguns de seus biógrafos (Perry, 1948; Matthiessen, 1961; Myers, 1986), sabe-se que William James cresceu em um lar muito particular, regido por um pai excêntrico, que propiciou ao seu primogênito um ambiente intelectual denso, o convívio com figuras proeminentes e uma formação educacional pouco ortodoxa passada em algumas cidades da Europa. Este mesmo ambiente peculiar produziu, pelo menos, mais um James brilhante: Henry, seu irmão mais velho e romancista de primeira linha. W. James é considerado por muitos o introdutor da psicologia nos Estados Unidos, enquanto disciplina emancipada da filosofia. Produziu, neste campo, um clássico: The Principles of Psychology (1890), do qual o Psychology: Briefer Course (1892) é uma versão abreviada e revisada. Entre outros livros, escreveu Pragmatism: A New Name for Some Old Ways of Thinking (1907), obra que o inscreve na história da filosofia como um dos fundadores do pragmatismo.

\section{Diz Myers:}

As realizações de James se estenderam para além dos campos da psicologia e da filosofia; por causa de suas crenças e atividades morais, sociais e políticas sua vida e seu pensamento tornaram-se uma parte essencial da história intelectual americana. Sua oposição ao imperialismo que ele reconhecia por detrás da América espanhola e de outras guerras, sua preocupação com um cuidado adequado aos doentes mentais, seu receio de que os direitos das minorias estivessem sendo desconsiderados, suas declarações socialistas em favor de uma distribuição igualitária da riqueza, suas tentativas de proteção a animais de laboratório (...) seus esforços em proteger os praticantes de formas alternativas de medicina (...) tudo isso fez dele uma figura permanente na história americana (1986, p.12).

2. Recorrendo a Darwin, James considera que um organismo age em um determinado ambiente e que este mesmo ambiente é um mundo pessoal, na medida em que, descartada a busca metafísica por mundos absolutos, são precisamente as ações do organismo que organizam o ambiente à sua volta. A imagem evocada por James é bastante distinta daquela outra que retrata um organismo sendo afetado pelas características ambientais de um meio preexistente. James prefere a imagem de um mundo que começa a se compor na medida em que um organismo começa a atuar sobre ele. Não se quer dizer com isso que não exista um mundo antes da existência de um organismo dotado da capacidade de ação sobre o mundo. O argumento aqui é o de que, na perspectiva do organismo em questão, bem como na perspectiva de outros organismos que partilhem com este referências ambientais básicas, o mundo começa a se organizar no ritmo e medida em que eles interagem ou, dito de outra forma, o mundo toma forma e torna-se passível de ser conhecido pelos organismos a partir de experiências interativas. 
No conjunto de textos sobre hábito, está inaugurada, em germe, uma parcela significativa dos conceitos jamesianos que aflorariam plenamente em escritos posteriores. Isto aparece com mais clareza quando se opera uma releitura dos textos psicológicos em termos menos neurofisiológicos. Mesmo no que diz respeito à noção de eu há, nestes textos, indicações iniciais importantes, como a de que "quando olhamos de fora para criaturas vivas, uma das primeiras coisas que nos ocorre é que elas são pacotes de hábitos” (James, 1890, p. 104). Ou na afirmação, igualmente impactante, de que "toda nossa vida, considerando-se que ela tenha uma forma definida, não é mais que uma massa de hábitos” (James, 1899a, p. 750). Neste conjunto temático estão identificados três tópicos principais.

Primeiro, o destaque dado à base física, ou neurofisiológica do hábito e sua implicação para os limites do aprendizado de novos hábitos ou da modificação de hábitos antigos.

Segundo, a apresentação do hábito como uma versão possível das ações adaptativas de um organismo em referência a um meio; ou seja, a ênfase sobre os aspectos funcionais do hábito.

Terceiro, a possibilidade de alteração dos hábitos pela ação voluntária e os efeitos ético-morais a ela correspondentes.

No primeiro tópico está presente um elemento central que é o do contraponto regular da preocupação de James em conceber o hábito em solo fisicalista com seu interesse em determinadas implicações de cunho ético. Fundamentalmente, ele lança metáforas naturalistas de efeitos teóricos e morais poderosos. Ou seja, James enuncia, com base em um vocabulário biológico, definições sintéticas de seus conceitos principais, mas de sintaxe suficientemente ampla para que ele próprio, mais adiante, estenda largamente suas possibilidades de significação. Sua metáfora central neste conjunto de textos é a de que “... um hábito adquirido, do ponto de vista fisiológico, é nada mais que uma nova via de descarga formada no cérebro pela qual, desde então, certas correntes aferentes tendem a seguir” (James, 1892, p. 137).

Seu argumento é construído inicialmente pela exploração das "propriedades fundamentais da matéria”, especialmente pela abordagem das possibilidades de modificação física estrutural pela influência de agentes externos. Citando exemplos como o de uma barra de ferro que pode tornar-se, estruturalmente falando, magnética ou cristalina sem a modificação de sua forma externa, ele recorre a noções da física newtoniana, como inércia e resistência, para compor um quadro dinâmico feito de impulsos elétricos sulcando a substância cerebral. Neste esquema, há uma condição fundamental para o bom funcionamento de seu sistema de compreensão: a qualidade de plasticidade do corpo físico a ser modificado, isto é, a capacidade de ser impressionável sem risco significativo de desintegração estrutural. A matéria orgânica em geral, e o tecido cerebral em particular, seriam 
especialmente plásticos, ${ }^{3}$ no sentido conferido por James, que resume assim sua idéia:

Os fenômenos do hábito em seres vivos são relativos à plasticidade dos materiais orgânicos dos quais seus corpos são compostos. (...)

As correntes (vindas através das raízes nervosas sensórias), uma vez nos (hemisférios cerebrais), devem encontrar uma saída. Ao saírem, deixam seus traços nas vias utilizadas. A única coisa que elas podem fazer, em resumo, é aprofundar vias antigas ou criar vias novas; e a plasticidade total do cérebro se resume muito quando nós o consideramos um órgão no qual as correntes que chegam pelos receptores fazem, sem dificuldades, vias que não desaparecem facilmente (ibid., p. 138-9).

Fundando hábito em terreno fisicalista, James submete a criação, a modificação e a recriação de hábitos às leis da fisiologia cerebral. Ele parece, neste ponto de sua obra, afirmar que um hábito seria, em última instância, uma impressão cerebral mais ou menos perene, indicando, dessa maneira, restrições à mobilidade na forma de um organismo se comportar e de agir habitualmente no mundo. Ficaria a impressão de que James concebe a vida, e o mundo que corresponde a ela, em larga medida, como propensos à cristalização, não fosse o fato de que o próprio James, não muito mais tarde, enfatizará a hegemonia do novo - novos movimentos, novos eus e novas formas de vida - como, permanentemente, dando entrada no mundo. ${ }^{4}$

3. É notável como James parece antecipar noções relativas ao funcionamento fisiológico do sistema nervoso central. São encontradas, em alguns autores contemporâneos, afirmações sintônicas com as de James sobre a plasticidade cerebral. Um bom exemplo é o do neurologista inglês Oliver Sacks $(1995,2000)$, que extrai da idéia de maleabilidade cerebral suas melhores conseqüências, como se verifica a partir do conteúdo da passagem mezzo teórica, mezzo biográfica, abaixo: "Estou escrevendo com a mão esquerda, embora seja completamente destro. Fui operado do ombro direito há um mês e atualmente não devo, não consigo usar o braço direito. (...) Estou desenvolvendo novos padrões e hábitos... uma identidade diferente, pode-se dizer, pelo menos nesta esfera específica. Devem estar ocorrendo mudanças em alguns programas e circuitos do meu cérebro - alterando cargas sinápticas, conexões e sinais (embora nossos métodos de obtenção de imagens cerebrais ainda sejam muito precários para mostrá-las). (...)

Para mim, como médico, a riqueza da natureza deve ser estudada no fenômeno da saúde e das doenças, nas infinitas formas de adaptação individual com que organismos humanos, as pessoas, se reconstroem diante dos desafios e vissicitudes da vida.

Nesta perspectiva, deficiências, distúrbios e doenças podem ter um papel paradoxal, revelando poderes latentes, desenvolvimentos, evoluções, formas de vida que talvez nunca fossem vistos, ou mesmo imaginados, na ausência desses males” (Sacks, 1995, p. 16-7; grifo meu).

4. O texto em que James aborda mais diretamente o tópico da presença regular de "novidade" no mundo é "The experience of activity" (1905). 
Aqui, podemos inserir um exemplo da releitura dos textos psicológicos jamesianos à luz de seus escritos posteriores. Retomando o que se convencionou, aqui, chamar de primeira metáfora naturalista, é possível colocar em suspenso a nomenclatura mais neurofisiológica e sustentar a afirmação mais simples de que um hábito é uma nova via.

Ao se destituir a primeira metáfora de termos como "correntes elétricas" e "descargas cerebrais", abre-se espaço para uma imagem de eu menos comprometida com o vocabulário da neurofisiologia. Esta imagem de eu, presente no segmento mais maduro da obra de James, tem como centro de referência conceitual um corpo humano e suas ações, mas não restringe seu alcance semântico à gramática do fisicalismo. Nesta versão mais livre da metáfora, um hábito pode ser entendido como uma regra de ação, como um dos componentes de uma forma de vida ou como o registro mnêmico de ações passadas. ${ }^{5}$

No segundo tópico, James reafirma a sua posição darwiniana ao destacar a utilidade adaptativa do hábito. Ao dissertar sobre os "efeitos práticos do hábito", James é claro: "Primeiro, o hábito simplifica nossos movimentos, os faz acurados e diminui a fadiga. (...) Segundo, o hábito diminui a atenção consciente com a qual realizamos nossos atos” (ibid., p. 140-1).

E, em seguida, James enuncia sua segunda metáfora naturalista: “Hábitos dependem de sensações não atendidas” (ibid., p. 143).

O fundamental aqui é notar o quanto é importante para um organismo a aquisição e manutenção da habilidade, ou capacidade, de fazer a atenção consciente repousar. Em outras palavras, não atender a uma sensação equivale a ascender a um tipo particular de repouso. Deixando toda uma série de atividades mais ou menos cotidianas ou banais, embora fundamentais à conservação da vida diária, a cargo do hábito, o organismo reserva à vida mental plenamente consciente outras tarefas e esforços.

James apresenta seu argumento da seguinte forma:

Se um ato requer para sua execução a cadeia $A, B, C, D, E, F, G$ etc. de eventos neurais sucessivos, então, nas primeiras performances da ação a consciência deverá deliberar, em cada um destes eventos, entre um conjunto de alternativas erradas que tendem a se apresentar; mas o hábito logo leva a que cada evento evoque seu próprio e apropriado sucessor sem qualquer outra alternativa independente e sem qualquer referência à vontade consciente, até que, finalmente, a cadeia inteira, $A, B, C, D, E, F, G$ se realize tão logo $A$ ocorra, tal como

5. Certamente, para a compreensão plena deste argumento, faltam algumas peças teóricas que estarão presentes sobretudo nos Essays in radical empiricism (reunião póstuma - 1912 - de artigos produzidos entre 1904 e 1905. 
se $A$ e o restante da cadeia fossem fundidas em um fluxo contínuo (a continuous stream). (James, 1890, p. 114)

Há, implícitos nesta passagem, dois elementos importantes. Primeiro, a necessidade de uma ação voluntária inicial antes da corrente de ações habituais: "Na ação habitual (...) o único impulso que os centros ideacionais e sensoperceptivos precisam deflagrar é o impulso inicial, o comando para iniciar” (ibid., p. 116).

Segundo, o retorno da atenção consciente na eventualidade de que algo “errado” ocorra: “... cada movimento da cadeia é em alguma medida acompanhado por algum tipo de consciência. Eles são sensações para as quais nós somos usualmente desatentos, mas que imediatamente chamam a nossa atenção se eles transcorrem com erro" (ibid., p. 118).

Finalmente, no terceiro tópico, são exploradas as "implicações éticas da lei do hábito”. James inicia este tópico com um preâmbulo cujo teor poderia facilmente incomodar os críticos do american way of life. No trecho seguinte, por exemplo, encontram-se afirmações que, à primeira vista, sugerem uma postura reacionária diante do mundo em geral e da organização social norteamericana em particular.

Hábito é, assim, a grande mola mestra da sociedade, seu agente mantenedor mais precioso. É ele sozinho que mantém todos nós dentro dos limites da lei e que salva os pobres e desvalidos de sentimentos invejosos e revoltosos. Ele sozinho previne que as mais duras e repulsivas condições de vida não sejam abandonadas por aqueles que as suportam. (...) Ele destina todos nós à luta diária dentro dos limites de nossa criação ou de nossas escolhas iniciais e ao desempenho, o melhor possível, de uma ocupação que desagrada, mas que nos é destinada por não sermos talhados para nenhuma outra e é tarde demais para começar tudo de novo. Ele impede que extratos sociais diferentes se misturem. (ibid., p. 121)

Além disso, fica no leitor a sensação de que um hábito, uma vez suficientemente assentado, torna a ordem social cristalizada e a personalidade engessada em suas possibilidades de renovação: por volta dos trinta anos, o caráter se fixa como gesso e nunca tornará a amolecer (ibid.).

Contudo, como se verá adiante, esta não é a sua posição.

Tendo como centro a idéia de que "nós devemos fazer automáticas e habituais as ações úteis, tão cedo possível e tanto quanto nos for possível fazer”, James propõe quatro "grandes máximas" em torno das relações entre as leis

6. Em um de seus textos sobre hábito - "The laws of habit” (1899a) - James inclui uma quinta grande máxima: "Don’t preach too much to your pupils or abound in good talk in the abstract" (p. 753). Esta afirmação, na verdade um prenúncio da quinta e última máxima, é uma recomen- 
morais e as leis do hábito. A primeira é assim enunciada por ele: “Na aquisição de um novo hábito, ou no abandono de um hábito antigo, nós devemos cuidar para iniciarmos tão fortemente e decididamente quanto pode ser uma iniciativa” (p. 123).

A segunda máxima, bastante conectada à primeira, é uma espécie de "dica” para o sucesso na criação habitual: "Nunca permita que uma exceção ocorra até que o novo hábito esteja seguramente enraizado em sua vida” (p. 123).

Já a terceira máxima é, em relação às duas anteriores, mais rica em suas implicações. Sobretudo por dar relevo à ação como elemento central na constituição do hábito. "Aproveite toda oportunidade possível para agir em acordo com cada decisão tomada e com cada impulso experimentado na direção dos hábitos a que você aspira. Não é no momento da formação dos hábitos, mas no momento em que produzem efeitos motores que resoluções e aspirações comunicam o novo set ao cérebro" (p. 124).

Por fim, a quarta máxima: "Mantenha a capacidade de esforço viva em você através de um pequeno esforço gratuito a cada dia. Isto é, seja sistematicamente ascético ou heróico em pequenos e desnecessários pontos...” (p. 126) ${ }^{7}$

Quão longe as reflexões de James sobre o hábito levarão os leitores, é questão a ser respondida com mais textos e mais estudo. A recompensa virá em dobro.

\section{Referências}

Angier, Roswell P. Another student's impressions of James at the turn of the century. Psychological Review, v. 50, p. 125-34, 1943.

Foucault, Michel. História da sexualidade 2: o uso dos prazeres. Rio de Janeiro: Graal, 1990.

L’herméneutique du sujet: cours au Collège de France (1981-1982). Paris: Gallimard/Seuil, 2001.

James, William (1887). A definition of habit. The manufacturer and builder, v. 19, n. 5, p. 116, May. (1890). Habit. The principles of psychology, New York, Dover, v. 1, 1950.

dação expressa aos professores, o que a torna plausível no contexto de uma palestra para educadores, mas, naturalmente, de presença imprópria ou dispensável em seus textos mais teóricos.

7. Esta máxima lembra as recomendações morais recolhidas por Foucault $(1990,2001)$ em seus textos sobre ascese. Nelas, também coincidem o alvo a ser alcançado pelos exercícios ascéticos e as ações que correspondem a estes mesmos exercícios. 
(1892). Habit (Psychology: briefer course). In: Writings 1878-1899. New

York: The library of America, 1992.

(1899a). The laws of habit. (Talks to teachers on psychology and to students on some of life's ideals). In: Writings 1878-1899. New York: The library of America, 1992.

(1899b). The gospel of relaxation (Talks to teachers on psychology and to students on some of life's ideals). In: Writings 1878-1899. New York: The library of America, 1992.

(1905). The experience of activity. In: Essays in Radical Empiricism. Lincoln/London: Bison, 1996.

Matthiessen, F. O. The James Family. New York: Knopf, 1961.

Myers, Gerald E. William James: his life and thought. New Haven/London: Yale, 1986.

Pragmatism and introspective psychology. In: Putnam, Ruth A. (org.). The Cambridge Companion to William James. Cambridge: Cambridge University, 1997.

Perry, Ralph Barton. The thought and character of William James. Cambridge: Harvard University Press, 1948.

Posnock, Ross. The influence of William James on America culture. In: Putnam, Ruth A. (org.). The Cambridge Companion to William James. Cambridge: Cambridge University, 1997.

SAcks, Oliver W. Um antropólogo em Marte: sete histórias paradoxais. São Paulo: Companhia das Letras, 1995.

Vendo vozes: uma viagem ao mundo dos surdos. São Paulo: Companhia das Letras, 2000. 